Carnegie-Rochester Conference Series on Public Policy 33 (1990) 221-256

North-Holland

\title{
THE QUALITY DIMENSION IN ARMY RETENTION
}

\author{
CHARLES BROWN* \\ University of Michigan \\ and \\ National Bureau of Economic Research
}

\begin{abstract}
Despite the relatively "egalitarian" (little pay for performance) structure of military compensation, those who do better on tests of proficiency in their military occupation are more likely to re-enlist than those who do worse, and this difference is not primarily due to the Army's unwillingness to allow its worst performers to re-enlist. In contrast, those with the best scores on the general ability test given prior to enlistment are less likely to re-enlist.
\end{abstract}

It is generally agreed that the U.S. military pay structure is "egalitarian" in that there is (relative to the civilian sector) little variation in pay among those with similar length of service (Baldwin and Daula, 1985, p. 354). Indeed, Smith, Sylwester, and Villa (1989) find that not only are schooling and high scores on the Armed Forces Qualification Test (AFQT) worth more in the civilian sector than in the Army to those contemplating re-enlistment, but also having an above-average promotion record during one's first term of military service is worth more outside the military as well.1 They conclude that "across all these indicators of employee performance....relative military-civilian compensation is lower for good performers."

At least in part as a result of the fear that the military's

\footnotetext{
* am grateful to participants at a conference sponsored by the U.S. Army Research Institute, at the University of Michigan Labor Workshop, and at the Carnegie-Rochester conference for comments on earlier orafts of this paper. David Smith and Stephen Sylwester provided a great deal of help with the intricacies of the data, and Thomas Hungerford and Marsha Silverberg handled the computer work with patience and skill.

'Smith, Sylwester, and Villa's measure of military compensation takes account of pay grade, promotion-linked pay increases, re-enlistment bonuses, and pensions. While the reenlistment bonuses vary significantly by occupation, being proportionally larger for jobs experiencing retention problems, within an occupation and grade they are a fixed fraction of regular pay.
} 
compensation system would be a barrier to recruiting and retaining able soldiers, there has been a persistent concern about the quality of those attracted by the all-volunteer force. (See, e.g., 0i's (1967, p. 45) early discussion of the education levels of true and draft-induced volunteers in estimating the cost of ending the draft. That this concern has continued can be seen from the title of Slackman's 1986 study for the Congressional Budget Office: "Quality Soldiers: Costs of Manning the Active Army.")

Studies of initial enlistment and of subsequent re-enlistment decisions offer a striking contrast in the treatment of the quality of those who are enlisting and those who are contemplating re-enlistment. The standard model of enlistment behavior, (Fisher (1969), DeVany and Saving (1982), Ellwood and Wise (1987)), has the number of high-quality recruits being driven by supply (the Army typically will take as many as wish to enlist), but the number of lower-quality enlistees is rationed by the Army so that total enlistments are equal to enlistment targets. 2 Quality of enlistees is typically measured by AFQT (Armed Forces Qualification Test) scores and high school graduation.

The quality issue deserves at least as much attention in re-enlistment studies as in analyses of initial enlistment, for three reasons. First, the usual presumption is that the value of individuals to an organization is more sensitive to their quality the higher their position (Rosen, 1982). Second, while the reluctance of the armed forces to pay very different wages to those with different levels of performance suggests attention to quality issues at all levels, this problem is to some extent finessed at the entry level by offering educational benefits which are differentially attractive to those who have completed high school and have good test scores. But this creates incentives for these same individuals to leave after completing their initial term of service (Hogan and Smith, 1988). Third, the quality of those who re-enlist remains a critical concern even for those who prefer to solve enlistment problems with a nonvolunteer force (draft, national service, etc.).

Despite the importance of the quality of those who remain in the

${ }^{2}$ Daula and Smith (1986) suggest that even high-quality enlistments reflect demand as well as supply forces. 
military, previous studies of re-enlistment (or, more broadly, retention) ${ }^{3}$ have paid too little attention to the quality issue. While quality indicators are often included as control variables in retention equations, the implications of those equations for the quality-mix of the those staying and leaving is not made clear. The typical study includes military and civilian pay as variables of central interest, and these (especially civilian pay) are estimated values based on the individual's quality indicators. With these (and other control variables which may have some correlation with the quality indicators) in the equation, the overall (i.e., non-ceteris-paribus) relationship between quality and retention is unclear. Moreover, quality continues to be measured by AFQT and high school graduation in most retention studies, even though the Army has observed (and to some extent conducted written evaluations of) actual performance.

Ward and Tan's (1985) analysis of the quality issue is probably the previous study which is closest in spirit to the analysis which follows here. They model quality as a latent variable, determined in part by AFQT and schooling, and quality in turn determines speed of promotion (which they take to be their ultimate quality indicator). They find those with more schooling or higher AFQT scores are less likely to re-enlist, but those with more of the unobserved quality (which, however, is related to observable promotion rates) are more likely to do so.

In contrast, this study treats education, AFQT, grade level, and scores on Army proficiency tests as quality indicators, thus putting less emphasis on promotion as the ultimate indicator of quality. One motivation for doing so is the fact that the Army has changed its "formula" for promotions, in part because of a recognition that it provided too many "promotion points" to attributes with too weak a relationship to performance. Thus, using promotion as the ultimate quality indicator is too restrictive. A second difference is that this study attempts to explicitly model the determinants of being ineligible to re-enlist among those who have completed their term of service. Since restricting eligibility is an alternative to performance-based pay in raising the

\footnotetext{
3"Attrition" refers to failure to complete the term of service to which one originally committed; "extension" refers to a (typically) short remaining in the Army beyond one's term of enlistment without agreeing to a longer (typically 3-4 year) term of further service. "Retention" can include re-enlistment, extension, or simply nonattrition.
} 
average quality of those who re-enlist, explicit consideration of ineligibility is warranted.

While the military differs from civilian employers in obvious and important ways, it shares with large civilian employers both employerspecificity of skills (0i, 1983a, p. 150, 1983b, pp. 71-80) and a tendency toward less merit-driven wage structures (Foulkes, 1980; Brown and Medoff, 1989). Whether this leads to problems retaining the most desired workers is less clear, though there are at least hints that this is the case (Musell (1986) on federal civilian workers and The Economist (1989) on 0xford faculty). The military therefore represents an interesting "case study" even for those more interested in civilian than military labor markets.

\section{A SIMPLE MODEL OF RE-ENLISTMENT AND QUALITY}

Let $x_{i}$ be the value to the military of an individual contemplating reenlistment, and let $M_{i}$ and $C_{i}$ be the level of utility achieved by individual $i$ by choosing to re-enlist in the military or leave for the civilian sector, respectively. Assume that $M$ and $C$ are linear in $X$,

$$
\begin{aligned}
& M_{\mathbf{i}}=m_{0}+m x_{i}+v_{i} \\
& c_{i}=c_{0}+c x_{i}+w_{i}
\end{aligned}
$$

and that $v_{i}$ and $w_{i}$ are uncorrelated with $x_{i}$. The latter assumption is nearly a definition: it says that $m$ and $c$ reflect not only the "true" effects of $x$ but also the effects of any other variables correlated with it. The individual chooses to re-enlist if $R \equiv M-C$ is positive, or, equivalently, if

$$
\begin{aligned}
R_{i} & =\left(m_{0}-c_{0}\right)+(m-c) x_{i}+\left(v_{i}-w_{i}\right) \\
& =b_{0}+b x_{j}+e_{j}>0
\end{aligned}
$$

It is worth stressing that $b=m-c$ reflects the relationship between "net advantages," not just pay, and $x_{i}$ - If those who are most productive in military careers are those who happen to like the military life more than others do, or if their commanders manage to organize nonwage 
compensation (choice assignments or the simple joys of recognition) to their advantage, $b$ may be positive despite the relative insensitivity of military pay to $X$. Foulkes (1980), for example, specifically mentions better assignments and recognition as ways of rewarding better performers in large nonunion companies that base pay on seniority rather than performance.

One can ask two questions of this simple model: (1) Are those who reenlist those who have the highest or the lowest values of $X$ ? (2) Will an increase in $b$ (say by making pay more sensitive to $X$ ) raise the average quality of those who stay?

The first question can be answered quite simply. Average quality conditional on deciding to re-enlist is $E(X \mid R>0)$. If $M$ and $C$ are exact functions of $x$, so that $e_{i}=0$ for all $i$, this conditional expectation is equal to $E\left(x \mid x>\frac{-b_{0}}{b}\right)$ if $b>0$ and $E\left(x \mid x<\frac{-b_{0}}{b}\right)$ if $b<0$ : those with the highest (lowest) value to the military choose to re-enlist if $b$ is positive (negative). Moreover, even if $e_{i}$ is nonzero, the same qualitative conclusions continue (in somewhat attenuated form) because $e$ is uncorrelated with $X$. This is illustrated in figure 1 , where the area $R>0$ corresponds to those choosing to re-enlist. Figure 1 is very similar to the model of Roy (1951) or its more recent application by Heckman and Sedlacek (1986) and Borjas (1987).

The second question receives a complicated answer in general, but a simple answer in a special case which is quite relevant to organizations like the military. The answer is illustrated in Figure 2. Suppose first that $b>0$ (left pane1). Then an increase in $b$ makes the $R=0$ line steeper. Those in area $G$ would not have reenlisted with the old $b$, but will now do so; those in area $L$ would have remained but now choose to leave. Since those in $G$ all have $X>0$ while those in $L$ all have $X<0$, it might appear that the average value of $x$ has increased. But this may be incorrect. The reason is that at each $e$, those in $G$ have lower $X$ than those who would have re-enlisted anyway (area $A$ ), and adding them may pull down the average. (A similar possibility was noted by Roy (1951, p. 138)).

In general, if $\bar{X}_{j}$ and $N_{j}$ are the average value of $x$ and the number of individuals in area $j$, respectively, the change in average $x$ due to the change in $b$ is

$$
\frac{\bar{x}_{A} N_{A}+\bar{x}_{G} N_{G}}{N_{A}+N_{G}}-\frac{\bar{x}_{A} N_{A}+\bar{x}_{L} N_{L}}{N_{A}+N_{L}} .
$$



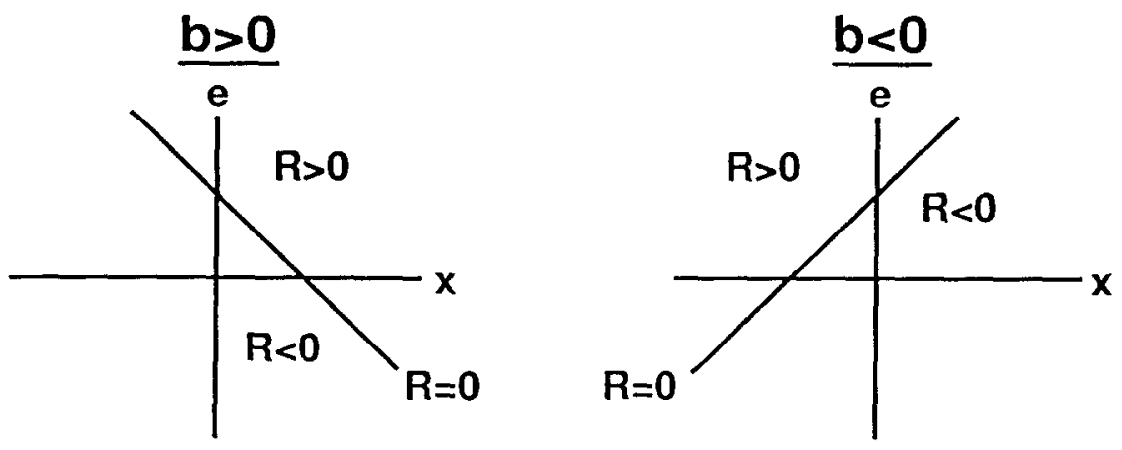

FIGURE 1

Who Re-Enlists?
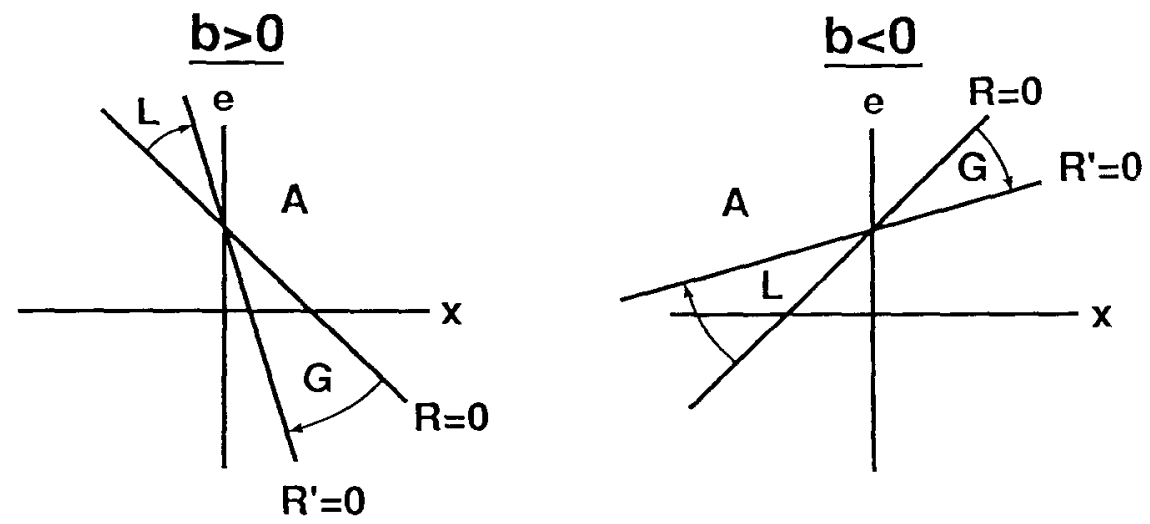

FIGURE 2

Making Pay More Sensitive to Performance 
This difference could be positive or negative. However, if $N_{G}=N_{L}$, the fact that $\bar{X}_{G}>\bar{X}_{L}$ is enough to make the change in average $x$ positive. This "special case" is of considerable practical importance. If, for example, $b$ were changed and Congress raised or lowered the pay of those at all quality levels in order to keep total re-enlistments constant, $N_{G}=N_{L}$ would be assured. (The new $R=0$ line would be parallel to the steeper one in the left panel of Figure 2, but higher or lower depending on what was needed to keep re-enlistments unchanged.)

A similar analysis applies if $b<0$ (right panel of Figure 2). Here an increase in $b$ makes the $R=0$ line flatter; $\bar{X}_{G}$ is again greater than $\bar{X}_{L}$. But now at each $e$ those in $L$ have higher $X$ 's than those in $A$, so their leaving tends to pul1 down $\bar{x}$. If $N_{G}=N_{L}$, we know that the average $x$ for those who re-enlist must rise, so the ambiguity is once aga in resolved in this case.

\section{MULTIPLE QUALITY INDICATORS, AND ELIGIBILITY STANDARDS}

Even with the relatively detailed Army records used in the empirical work reported below, we do not directly observe the individual's value to the military. Therefore, for empirical analysis we need to generalize the notation of the previous section so that $X$ now includes a set of indicators of quality, both entry characteristics such as schooling and AFQT scores and indicators of subsequent performance, and a constant term. Thus

$$
\mathbf{R}=\mathbf{X B}+\mathbf{e}
$$

and an individual re-enlists if this index is sufficiently high. Because $x$ includes a constant, we can arbitrarily set the critical value of $R$ which divides those who wish to re-enlist from those who do not at zero, and so

$$
\text { re-enlist iff } R>0 \text {. }
$$

However, condition (2) neglects the fact that the Army does not accept al1 those who wish to re-enlist. Instead, it excludes those whose performance is below some eligibility standard. The obvious statistical model is therefore

$$
E=X A+u
$$


and

$$
\text { re-enlist iff } R>0 \text { and } E>0
$$

(In (2'), quality is "measured" so that $E=0$ is he threshold level of quality for eligibility to re-enlist.)

Separate identification of the parameters of equations (1) and (3) depends on the Army designating some individuals as ineligible to reenlist: in effect, distinguishing discharges from quits. That distinction is not meaningful in contexts where the parties to a relationship can easily renegotiate the division of the "surplus" generated by that relationship. In this situation any separation indicates that the relationship was not generating any surplus, but who initiated the separation is not very informative. However useful the easy-renegotiation framework may be in other contexts, it is not the right model for understanding Army re-enlistments; those who manage re-enlistment are not free to match outside offers or otherwise adjust monetary compensation to avert jointly inefficient separations.

Equations (1) and (3) and condition (2') are the basis for the empirical work in this paper. This simple model highlights two ways in which the Army might avoid the "brain drain" that its compressed pay structure might otherwise provoke. First, those who are most valuable have a positive preference for the military, either because doing their work well makes the work more attractive or because their superiors arrange the nonpecuniary aspects of military life to their advantage. The good-workersare-happy-workers possibility seems to be most promising in those fields (e.g., infantry) with few civilian analogues. Second, the military may make staying sufficiently attractive that significantly more want to reenlist than are needed; it can then select among those willing to re-enlist rather than simply accepting the soldiers' self-selection decisions.

\section{DATA}

The data for this paper are drawn from the Army Research Institute Enlisted Personnel Data Base, a compilation of Army personnel data supervised by David Smith (see Smith, Sylwester, and Villa, 1989). The compilation began with a 25-percent sample of all enlisted accessions in the U.S. Army during fiscal years 1974-1984. The Enlisted Accession File contains information about the individual as of his/her entry into the Army 
(e.g., schooling, AFQT score, initial assignment). For each individual in the 25-percent sample, Master/Loss files were searched in subsequent years, and the last such record in each fiscal year for that individual was retained. The Master/Loss file, as its name implies, contains information on separations from the Army; it also includes information on reenlistment and other extensions of the service contract. For our purposes, a critical further source of data is the 1980-86 file of scores on the "Skill Qualification Test" (SQT), which characterizes individuals' proficiency in their occupational specialty after completing training (and periodically thereafter).

The file described so far contains information for over 300 thousand individuals. In order to keep the project to a manageable scope, it was decided to restrict the analysis to those in three "career management" fields: infantry, mechanical maintenance, and administration. (The latter group should be thought of as including office support staff rather than top decision-makers.) In addition, I focused on those deciding on a first re-enlistment during fiscal years 1985-87. This decision was based on the fact that, while SQTs became operational in fiscal year 1977, as late as fiscal year 1984 a significant fraction of the en1isted force had no SQT score in their files (Grafton and Horne, 1985, pp. 2-3). Since the most common term of enlistment is three years, this means the analysis is restricted to those whose initial enlistments occurred after the large increases in military pay in 1980-81 and who had much better test scores and high school graduation rates than those of cohorts entering a few years earlier.

Because my focus is on the decision to re-enlist, I concentrate on those who reach the re-enlistment decision -- i.e., who remain in the Army unt11 (near) the end of their initial commitment. 4 Specifically, those who leave more than six months prior to completing their initial commitment are

\footnotetext{
${ }^{4}$ Defining the end of the initial term of service is more complicated than it may seem. When an individual enlists initially, it is for a definite term of service (most often three years). An eligible individual may decide to re-enlist starting at the expiration of the previous commitment, or in some cases shortly before. However, for a variety of reasons an individual may also "extend" this commitment for a shorter (typically less than two-year) period. Extensions require either a considerable complication of the analysis (if treated as a separate outcome) or an essentially arbitrary decision to ignore them. Following most research on the topic, I have done the latter--if an individual with a 3-year initial commitment extends for one year, it is treated as if the individual's initial commitment had been 4 years (and had not been extended).
} 
excluded from the analysis. Thus, the focus is on re-enlistment conditiona? on completing the first term of service, not the unconditional reenlistment rate. Warner and Solon (1989) find little evidence of selectivity bias in estimating first-term re-enlistment equations in their sample from the Enlisted Personnel Data Base (1974-83 infantry enlistees), though they caution that this finding need not hold as a general rule.

Most but not all of those who leave the Army after completing their first term of service could have re-enlisted had they chosen to do so. I count as "ineligible" those who are disqualified from re-enlisting due to either a waivable or non-waivable disqualification. 5

One complication of judging eligibility is that it may not be determined independently of the individual's decision to re-enlist. Some re-enlistment bars arise because of action taken by one's commanding officer and, because they require considerable effort, may not be imposed on an individual who clearly intends not to re-enlist. On the other hand, individuals with bars to re-enlistment may succeed in getting them removed if they are serious enough about re-enlisting. Thus, in terms of our mode1, the threshold of performance below which one is deemed ineligible in these data may be different from those with $R>0$ than for those with $R<0$, and the difference may be either positive or negative. The threshold is allowed to vary this way when the model is estimated.

We have three types of individual attributes whose impact on reenlistment and eligibility are investigated. The first is high school graduation, which is represented by dummy variables for graduates and those who received a GED (general educational development high school equivalence); the omitted group is those who neither graduated nor obtained a GED. AFQT scores are measured in percentile terms, using renormed test scores introduced in 1984. Both high school graduation status and AFQT are measured at time of entry into the Army rather than at the time the reenlistment decision is being made.

Our SQT measure was obtained by starting with the SQT score for the year in which the re-enlistment decision is being made, and going to earlier years as necessary to $f$ ind a score for each individual. However, mean SQT scores vary widely from one military occupational specialty to the next, in a way seemingly unrelated to the technical complexity of the MOS,

\footnotetext{
5 Both the Army's "Re-enlistment Eligibility" codes and the "Inter-service Separation Code" were scanned for evidence of such disqualifications.
} 
and from year to year. Moreover, one is tested at a different "level" depending on one's pay grade (SQT level = grade-3, but with level 1 applying to pay grades E4 and lower). Therefore, a standardized SQT score was computed, subtracting the mean and dividing by the standard deviation of scores in the relevant occupation-level-year cell. Once these noncomparabilities across level, occupation, and year have been overcome, "there is little disagreement that the scores of soldiers taking a specific SQT accurately reflect differences in performance" (Grafton and Horne, 1985, p. 3). In addition to this normalized score, the level of the SQT taken was also included; it measures how fast the individual has been promoted as well as the level of the SQT test.

\section{SIMPLE TABULATIONS}

The tendency for military pay to be less sensitive to observable indicators of enlistee quality than is civilian pay suggests that retention of the best enlisted personnel may be difficult. Tables 1-3 contain simple tabulations which address this concern.

In each table, three possible outcomes are identified: re-enlistment, normal separation (i.e., separation at expected termination of service (ETS) date with no bar to re-enlistment), and ineligible separation (i.e., separation at ETS but ineligible to re-enlist). For those with particular levels of a quality indicator (e.g., AFQT scores in the lowest 30 percentiles), the probability of each outcome conditional on (at least nearly) reaching ETS is indicated.

Results for infantry are presented in Table 1. The first panel gives fairly dramatic reinforcement to the concern about quality of those who reenlist. Reenlistment is lower for those with higher AFQT scores. Ineligibility to re-enlist is also lower anong those with good AFQT scores.

The second panel presents a similar tabulation, but with high school graduation as the quality indicator. The main result here is that high school graduates are more likely to be eligible to re-enlist, but no more likely to do so. Perhaps surprisingly, those with GED high -school equivalences do not exhibit behavior between those with a diploma and those with a no-high-school credential: GEDs are less likely to re-enlist (and less likely to be eligible) than are other groups.

The third panel presents retention outcomes for those with differing SQT scores. While the differences between SQT-score groups are not 
Table 1

Outcomes by Enlistee Characteristics

Infantry, 1985-87

\begin{tabular}{|c|c|c|c|c|}
\hline \multirow{3}{*}{ Characteristic } & \multicolumn{3}{|c|}{ Percent Probability of } & \multirow{3}{*}{$\begin{array}{l}\text { Number } \\
\text { of Cases }\end{array}$} \\
\hline & \multicolumn{3}{|c|}{ Norma 1} & \\
\hline & Re-enlistment & Separation & Ineligibility & \\
\hline AFQT $1-30$ & 35 & 49 & 17 & 1904 \\
\hline AFQT $31-49$ & 33 & 54 & 14 & 2215 \\
\hline AFQT $50-64$ & 28 & 57 & 15 & 1234 \\
\hline AFQT $65+$ & 24 & 65 & 11 & 2267 \\
\hline Education < HS Grad & 30 & 47 & 23 & 544 \\
\hline Education = GED & 24 & 52 & 24 & 183 \\
\hline Education = HS Grad & 30 & 57 & 13 & 6900 \\
\hline SQT $<-.5$ & 28 & 52 & 20 & 1593 \\
\hline SQT -.5 to .5 & 30 & 56 & 14 & 2871 \\
\hline $\mathrm{SQT}>.5$ & 32 & 59 & 9 & 2319 \\
\hline SQT Leve $1=1$ & 28 & 57 & 15 & 6198 \\
\hline SQT Level > 1 & 52 & 45 & 3 & 599 \\
\hline SQT Level Missing & 27 & 59 & 14 & 830 \\
\hline
\end{tabular}


enormous -- neither enlistee decisions nor Army eligibility decisions are deterministic functions of SQT -- they suggest that those with higher SQI scores are more likely to re-enlist and less likely to be ineligible to stay beyond their first term. The fourth panel is consistent with this view: those who take the SQT at a higher level (i.e., have reached a higher pay grade) are likely to remain. This is not surprising, but it was not predictable either; civilian earnings of those who are promoted faster are also higher than those who are less quickly promoted while in the military. The final line of the table shows the proportion of the sample with missing SQT level (and missing SQT scores). ${ }^{6}$ These account for about 10 percent of the overall sample and the proportion missing does not vary a great deal across outcomes.

Similar tabulations for those making re-enlistment decisions in 198284 are presented in Appendix Table Al. The sample proportions for the various quality indicators are quite different (proportionally fewer high school graduates and high AFQT scores). However, for a given quality indicator, the patterns of retention outcomes are broadly similar, the main difference being evidence of higher re-enlistment rates for high school graduates.

Results for mechanical maintenance are presented in Table 2. These results are broadly similar to those for infantry, with some differences on subtler points. Those with higher AFQT scores are again less likely to reenlist or to be ineligible. High school graduates are somewhat more likely to re-enlist, and again more likely to be eligible to do so. The same holds for those with high SQT scores and in higher grades who take the higher level SQT'S. Missing SQT data are somewhat more common here than in Table 1, and those with missing SQT's are less likely to re-enlist (by about 5 percentage points).

Similar tabulations for those in mechanical maintenance facing reenlistment decisions in 1982-84 are presented in Table A2. Again the broad patterns of the later data can be seen here. The unavailability of SQT scores is much more striking here than in the infantry results for the same years in Table Al.

Outcomes for those in administration appear in Table 3. Those with higher AFQT scores are again less likely to re-enlist and more likely to be

\footnotetext{
${ }^{6}$ Because few cases had missing information about high school or AFQT, these frequencies are not shown in the table.
} 
Table 2

Outcomes by Enlistee Characteristics

Mechanical Maintenance, 1985-87

\begin{tabular}{|c|c|c|c|c|}
\hline \multirow{3}{*}{ Characteristic } & \multicolumn{3}{|c|}{ Percent Probability of } & \multirow{3}{*}{$\begin{array}{l}\text { Number } \\
\text { of Cases }\end{array}$} \\
\hline & \multicolumn{3}{|c|}{ Norma 7} & \\
\hline & Re-enlistment & Separation & Ineligibility & \\
\hline AFQT $1-30$ & 38 & 46 & 16 & 1859 \\
\hline AFQT $31-49$ & 34 & 53 & 13 & 2194 \\
\hline AFQT $50-65$ & 31 & 55 & 14 & 926 \\
\hline AFQT $65+$ & 31 & 57 & 12 & 987 \\
\hline Education < HS Grad & 32 & 45 & 23 & 597 \\
\hline Education $=$ GED & 37 & 43 & 20 & 203 \\
\hline Education $=$ HS Grad & 35 & 53 & 13 & 5175 \\
\hline SQT $<-.5$ & 30 & 51 & 19 & 1261 \\
\hline SQT -.5 to .5 & 37 & 50 & 13 & 2073 \\
\hline SQT $>.5$ & 37 & 52 & 11 & 1691 \\
\hline SQT Level = 1 & 34 & 52 & 14 & 4774 \\
\hline SQT Level > 1 & 59 & 34 & 7 & 259 \\
\hline SQT Level Missing & 30 & 55 & 15 & 943 \\
\hline
\end{tabular}


Table 3

Outcomes by Enlistee Characteristics

Administration, 1985-87

\begin{tabular}{|c|c|c|c|c|}
\hline \multirow{3}{*}{ Characteristic } & \multicolumn{3}{|c|}{ Percent Probability of } & \multirow{3}{*}{$\begin{array}{l}\text { Number } \\
\text { of Cases }\end{array}$} \\
\hline & \multicolumn{3}{|c|}{ Norma 1} & \\
\hline & Re-enlistment & Separation & Ineligibility & \\
\hline AFQT $1-30$ & 53 & 32 & 15 & 530 \\
\hline AFQT $31-49$ & 47 & 42 & 12 & 733 \\
\hline AFQT $50-64$ & 40 & 53 & 8 & 367 \\
\hline AFQT $65+$ & 32 & 59 & 9 & 775 \\
\hline Education < HS Grad & 56 & 24 & 20 & 121 \\
\hline Education = GED & 47 & 37 & 16 & 38 \\
\hline Education = HS Grad & 41 & 48 & 10 & 2248 \\
\hline$S Q T<-.5$ & 42 & 42 & 16 & 644 \\
\hline $\mathrm{SQT}-.5$ to .5 & 44 & 47 & 10 & 722 \\
\hline $\mathrm{SQT}>.5$ & 47 & 46 & 7 & 701 \\
\hline SQT Leve1 = 1 & 42 & 47 & 11 & 1916 \\
\hline SQT Leve1 > 1 & 68 & 29 & 2 & 163 \\
\hline SQT Level Missing & 31 & 58 & 11 & 328 \\
\hline
\end{tabular}


eligible to do so. High school graduates are more likely to be eligible to re-enlist but less likely to do so. Those with higher SQT scores and SQT level are again more likely to re-enlist and to be eligible. About 15 percent have missing SQTS, and there is a clearer tendency for these to be those who do not re-enlist. Similar patterns (but with no effect of high school graduation on re-enlistment) are evident in the tabulations for 1982-84 decisions in Table A3.

\section{A MORE FORMAL ANALYSIS}

The model described by equations (1) and (3) and condition (2') would treat the probability of re-enlistment as $\operatorname{Prob}(R>0, Q>0)$, the probability of a normal separation as $\operatorname{Prob}(R<0, Q>0)$, and the probability of an "ineligible" separation as $\operatorname{Prob}(Q<0)$. However, as noted in discussing the data, the threshold for eligibility to re-enlist could be either higher or lower than that for those who have no such desire. Consequently, define $\theta$ as the threshold for re-enlistment eligibility for those not desiring to do so. Then the probability of re-enlisting is again $\operatorname{Prob}(R>0, Q>0)$, but the probability of normal separation is $\operatorname{Prob}(R<0, Q>\theta)$ and one minus the sum of these two probabilities is the probability of an ineligible separation.

In obtaining the estimates of $B$ and $A$, it was assumed that $e$ and $u$ came from a bivariate normal distribution, each having mean zero and variance one, and a correlation between them of $\rho$. Normality is neither obvious nor innocuous, but alternative distributions with nonzero correlation between $e$ and $u$ are much more difficult to implement. Since $\rho$ (and, to some extent, $\theta$ ) are identified by (arbitrary) functional form assumptions rather than coefficient restrictions derived from theory, and because obtaining convergence with all parameters free proved elusive (a not uncommon problem in such models), estimates are presented for $\theta=\rho=0$, and for combinations of $\theta$ from -1 to +1 and $\rho$ from -.5 to .5 . The first combination $(\theta=\rho=0)$ is a sensible place to start given that there is no particularly strong presumption about the sign of either $\theta$ or $\rho$.

The estimation was done using the GQOPT nonlinear optimization routine (Quandt and Goldfeld, 1984). The standard errors were calculated using the BHHH method (Berndt, Hall, Hall, and Hausman, 1974); these were checked against those obtained from inverting the matrix of second-partial derivatives of the log-likelihood function (and there were no noteworthy discrepancies). 
Table 4

Re-enlistment Model for Infantry

\begin{tabular}{|c|c|c|c|c|}
\hline \multirow{2}{*}{$\begin{array}{l}\text { Explanatory } \\
\text { Variable }\end{array}$} & \multicolumn{2}{|c|}{$\begin{array}{c}\text { Coefficients in } \\
\text { Equation for }\end{array}$} & \multicolumn{2}{|c|}{$\begin{array}{l}\text { Derivative of } \\
\text { Probability of }\end{array}$} \\
\hline & $R$ & $E$ & Re-enl & N Sep \\
\hline \multicolumn{5}{|c|}{$\theta=0, \quad \rho=0, \quad L L F=-6295.12$} \\
\hline \multirow[t]{2}{*}{ Constant } & .228 & .640 & & \\
\hline & $(2.81)$ & $(7.66)$ & & \\
\hline \multirow[t]{2}{*}{ H.S. Graduate } & -.202 & .388 & -.034 & .122 \\
\hline & $(2.86)$ & $(5.69)$ & & \\
\hline \multirow[t]{2}{*}{ GED } & -.127 & -.021 & -.040 & .035 \\
\hline & $(.93)$ & $(.16)$ & & \\
\hline \multirow[t]{2}{*}{ AFQT Score } & -.983 & .134 & -.286 & .316 \\
\hline & $(11.90)$ & $(1.41)$ & & \\
\hline \multirow[t]{2}{*}{ SQT Score } & .104 & .175 & .043 & -.004 \\
\hline & $(5.10)$ & $(8.24)$ & & \\
\hline \multirow[t]{2}{*}{ SQT Level } & .620 & .757 & .239 & -.067 \\
\hline & $(10.83)$ & $(7.35)$ & & \\
\hline \multicolumn{5}{|c|}{$\theta=-1, \quad \rho=-.5, \quad L L F=-6294.47$} \\
\hline \multirow[t]{2}{*}{ Constant } & .521 & .562 & & \\
\hline & $(7.20)$ & $(5.86)$ & & \\
\hline \multirow[t]{2}{*}{ H.S. Graduate } & -.311 & .388 & -.033 & .124 \\
\hline & $(5.03)$ & $(4.96)$ & & \\
\hline \multirow[t]{2}{*}{ GED } & -.086 & -.029 & -.031 & .032 \\
\hline & (.73) & $(.20)$ & & \\
\hline \multirow[t]{2}{*}{ AFQT Score } & -.862 & -.130 & -.287 & .324 \\
\hline & $(11.41)$ & $(1.18)$ & & \\
\hline \multirow[t]{2}{*}{ SQT Score } & .023 & .227 & .044 & -.005 \\
\hline & $(1.27)$ & $(9.20)$ & & \\
\hline \multirow[t]{2}{*}{ SQT Level } & .419 & .938 & .282 & -.143 \\
\hline & $(7.50)$ & $(8.62)$ & & \\
\hline
\end{tabular}

Sample probabilities: Re-enlist, .302; Normal separation, .558;

Ineligible $=.140 ; N=6790$.

T-ratios in parentheses below coefficients. 
Estimates for those in the infantry, conditional on both $\theta$ and $\rho$ being <ero, are presented in the top panel of Table 4. The first column contains the estimates of the determinants of $R$, the latent variable which governs the individual's willingness to re-enlist. Those with higher AFQT scores and those with high school diplomas are less likely to desire to re-enlist, while those with higher SQT scores and whose SQT tests are at a higher level (i.e., those who have been promoted in the past) are more likely to do so. The second column presents the relationship between these same variables and $E$, the latent variable governing eligibility to re-enlist. Those with diplomas, good SQT scores, and higher SQT level are more likely to be eligible to re-enlist; those with higher AFQT scores are more likely to be eligible, too, but this link is not statistically significant.

Interpreting these two columns of coefficients is complicated by the fact that the model relates observables to latent variables, while our sense of importance of effects depends on their impact on observable probabilities. Therefore, the effect of the variables on the probability of re-enlisting (Prob $R>0, Q>0$ ) is presented in column 3, while the effect on probability of normal separation $(\operatorname{Prob}(R<0, Q>\theta))$ is presented in the final column. The sum of these two represents the effect on the probability of being eligible to re-enlist. One can think of these as multivariate versions of the simple tabulations in Tables 1-3.

The effect of high school graduation on the probability of reenlisting is small, while its effect on the probability of normal separations is greater: the implied reduction in the probability of being barred from re-enlisting $(.088)$ is large given that only 14 percent of the sample is ineligible. Those with GEDs are less likely to re-enlist and more likely have normal separations; these effects are statistically fragile and so they should be given little weight. The negative effect of AFQTs on re-enlistment is paired with a near-equal increase in normal separations, the implied effects on eligibility being small. Higher SQTs and SQT level increase the probability of re-enlistment, with a similarly-sized increase in eligibility. Finally, while the standard deviation of SQT is by construction 1.0, one standard deviation of AFQT score is .23 (AFQT being uniform on $(0,1)$ in the population). Therefore, a one-standard deviation increase in AFQT reduces the probability of re-enlistment by about .067 , while a one-standard deviation increase in SQT raises it by .043 .

While the other $\theta, \rho$ combinations produced log-likelihoods which were not very different from that for $\theta=\rho=0$, and so there is no strong basis for preferring alternative values, the combination preferred by the likelihood 
function was $\theta=-1, \rho=-.5$. Estimates of the other parameters of the model conditional on these values are presented in the bottom panel of Table 4. The most important difference between the two panels is that SQT scores have a smaller and statistically more fragile impact on desire to re-enlist. Nevertheless, it remains true that those with higher SQT scores are more likely to re-enlist by an important margin.

Parameter estimates conditional on other values of $\theta$ and $\rho$ are presented in Appendix Table A4. There are few surprises. The negative impact of high school graduation on desire to re-enlist varies over a wide range with the assumed values of $\theta$ and $\rho$, while the impact of SQT Scores is consistently positive. The impact of AFQT on $E$ proves sensitive to choice of $\theta$ and $\rho$. Comparing the derivatives of the re-enlistment and normal separation probabilities shows an impressive consistency: it is partitioning these derivatives into effects on $R$ and $E$ which is more sensitive to $\theta$ and $\rho$.

The SQT score used in both Table 4 and Table A4 was chosen by starting with the decision year and working backward to earlier years if necessary. This gives the last (through decision year) available SQT score, a choice which might be challenged on two grounds. First, those who decide to re-enlist might be more likely to "cram" for the SQT, in effect overstating their day-to-day performance. Second, it is possible the SQT score we have comes from a test taken after the re-enlistment decision.

To see whether these concerns could be important, the analysis was redone using the second-last SQT (from a year before the decision) instead of the latest whenever more than one was available. The effects of SQT scores on $R$ were about $3 / 4$ as large as in Tables 4 and $A 4$, with a similar pattern of statistical significance. However, the $\theta=-1, \rho=-.5$ pair was the one least preferred by the data, and for the remaining pairs the $t$ ratio for the SQT score was 3.2 or higher.

Estimates for those in mechanical maintenance are presented in Table 5. Probably the most striking result is the similarity to those estimates in Table 4. In Table 5, high school graduation has a much weaker (negative) impact on desire to re-enlist, though the positive impact on eligibility to do so remains strong. GED effects are again statistically very weak. Those with higher AFQT scores are again much less likely to re-enlist than those with lower scores; this impact is only about $3 / 4$ as large as it was for those in infantry. Those with higher SQT scores are again more likely to re-enlist, though the impact of SQT scores on desire to re-enlist is barely significant statistically when $\theta=-1$ and $\rho=-.5$. SQT level is 
Table 5

Re-enlistment Model for Mechanical Maintenance

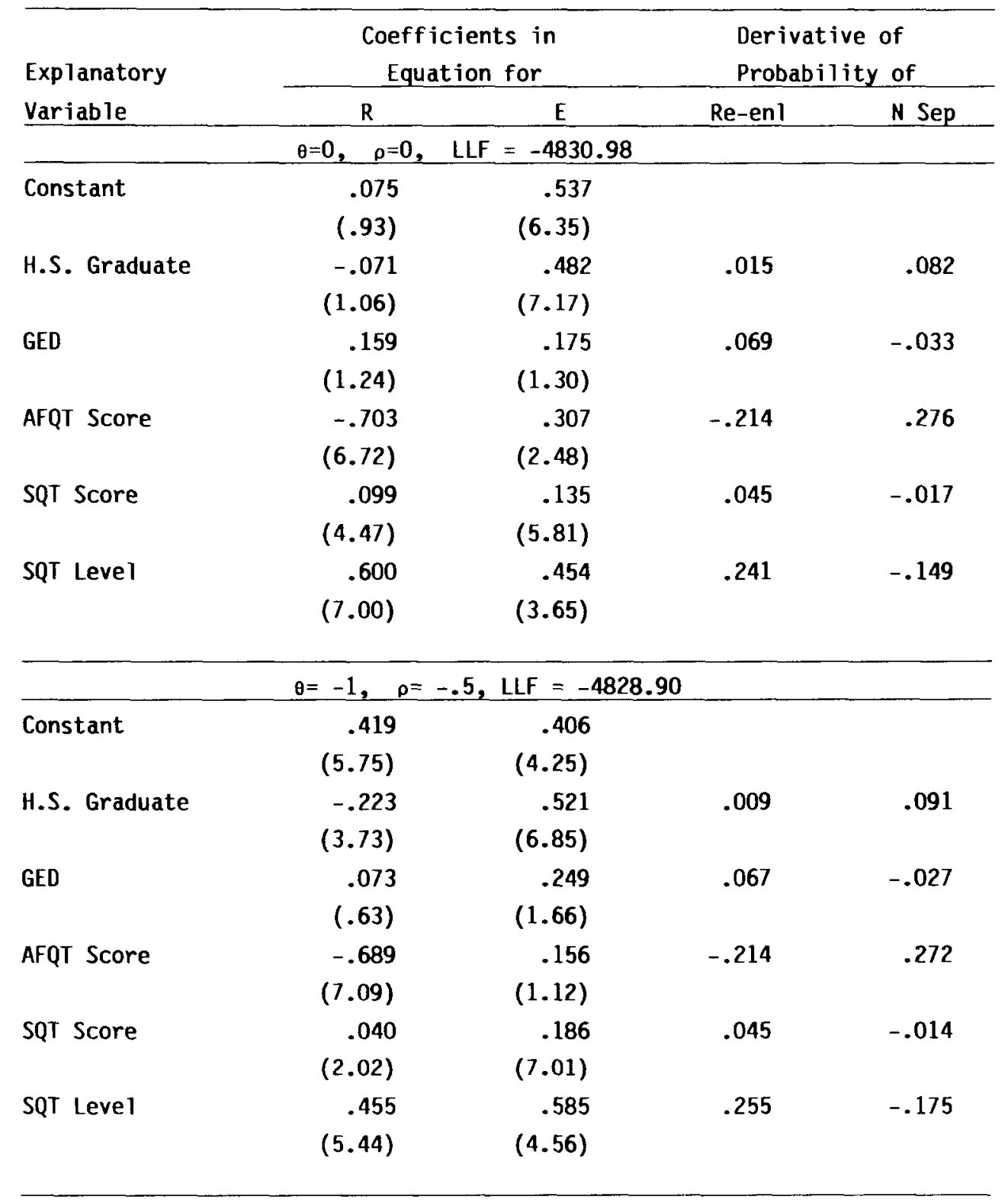

Sample probabilities: Re-enlist, .351; Normal separation, .512;

Ineligible $=.137 ; \mathrm{N}=5023$.

T-ratios in parentheses below coefficients. 
again associated with greater probabilities of wanting to re-enlist and being eligible to do so.

Results for other $\theta$, $\rho$ combinations appear in Appendix Table A5. It is also quite similar to the corresponding table for those in infantry: the effect of high school graduation on desire to re-enlist, and of AFQT on eligibility to do so, are again sensitive to the choice of those parameters. Using second-last SQT scores reduced the SQT impacts on $R$ by about a third and essentially eliminated it for the preferred $\theta=-1, \rho=-.5$ parameter set.

Finally, results for those in administration are presented in Table 6 . Again, the similarity of these results to those for the other career management fields is striking. The relationships between quality indicators and desire to re-enlist (negative for high school graduation, strongly negative for AFQT, positive for SQT score and level) from earlier tables reappear. Indeed, the positive effect of SQT scores is now statistically virile even for $\theta=-1$ and $\rho=-.5$. High school graduation and SQT Scores and level are positively related to quality; the weakness of AFQT in the equation for $E$ also persists.

The combined effects of the Bs and As on the probabilities of reenlisting and being eligible to do so are also similar to those in earlier tables. High school graduation has a huge effect on being eligible to reenlist (derivative $=.116$, versus sample mean ineligibility rate of .107). AFQT's negative effect on re-enlistment is matched by a larger increase in normal separations; the positive effect of SQT scores and level on reenlistment comes from both fewer normal separations and less probability of being ineligible to re-enlist.

In general, these patterns are even less sensitive to choice of $\theta$ and o than for infantry or mechanical maintenance (see bottom panel of Table 6 , and Appendix Table A6). Substitution of next-to-last SQT scores when possible reduced the SQT's effect on $R$ by about 1/4, but the smaller coefficients were uniformly significant statistically.

There are two fundamental determinants of the quality of those who reenlist -- the extent to which net advantages of re-enlisting are correlated with the quality indicators, and the extent to which eligibility bars prevent those with low quality but high eagerness to re-enlist from doing so. With the exception of AFQT, the other quality indicators consistently show the expected positive effect on eligibility, but with ineligibility rates of only 11-14 percent one would expect the impact of eligibility bars on average values of observable quality indicators to be fairly modest. 
Table 6

Re-enlistment Model for Administration

\begin{tabular}{|c|c|c|c|c|}
\hline \multirow{2}{*}{$\begin{array}{l}\text { Explanatory } \\
\text { Variable }\end{array}$} & \multicolumn{2}{|c|}{$\begin{array}{c}\text { Coefficients in } \\
\text { Equation for }\end{array}$} & \multicolumn{2}{|c|}{$\begin{array}{l}\text { Derivative of } \\
\text { Probability of }\end{array}$} \\
\hline & $\mathbf{R}$ & $E$ & Re-en I & N Sep \\
\hline & $\theta=0, \quad \rho=0, \quad L L F$ & $=-1895.01$ & & \\
\hline \multirow[t]{2}{*}{ Constant } & 1.182 & .645 & & \\
\hline & $(7.49)$ & $(3.80)$ & & \\
\hline \multirow[t]{2}{*}{ H.S. Graduate } & -.502 & .438 & -.041 & .157 \\
\hline & $(3.49)$ & $(2.96)$ & & \\
\hline \multirow[t]{2}{*}{ GED } & -.346 & .169 & -.055 & .100 \\
\hline & $(1.29)$ & $(.55)$ & & \\
\hline \multirow[t]{2}{*}{ AFQT Score } & -1.490 & .343 & -.313 & .404 \\
\hline & $(10.11)$ & $(1.81)$ & & \\
\hline \multirow[t]{2}{*}{ SQT Score } & .167 & .107 & .064 & -.036 \\
\hline & $(5.07)$ & $(2.85)$ & & \\
\hline \multirow[t]{3}{*}{ SQT Leve 1} & .633 & .741 & .311 & -.114 \\
\hline & $(5.55)$ & $(3.57)$ & & \\
\hline & $\theta=-1, \quad \rho=-.5$, & $L L F=-1894.96$ & & \\
\hline \multirow[t]{2}{*}{ Constant } & 1.351 & .697 & & \\
\hline & $(9.14)$ & $(3.86)$ & & \\
\hline \multirow[t]{2}{*}{ H.S. Graduate } & -.564 & .400 & -.046 & .157 \\
\hline & $(4.22)$ & $(2.54)$ & & \\
\hline \multirow[t]{2}{*}{ GED } & -.360 & .165 & -.052 & .100 \\
\hline & $(1.43)$ & $(.50)$ & & \\
\hline \multirow[t]{2}{*}{ AFQT Score } & -1.420 & .104 & -.343 & .394 \\
\hline & $(10.18)$ & $(.50)$ & & \\
\hline \multirow[t]{2}{*}{ SQT Score } & .123 & .144 & .068 & -.034 \\
\hline & $(4.01)$ & $(3.51)$ & & \\
\hline \multirow[t]{2}{*}{ SQT Leve 1} & .507 & .826 & .339 & -.140 \\
\hline & $(4.51)$ & $(3.91)$ & & \\
\hline
\end{tabular}

Sample probabilities: Re-enlist, .440; Normal separation, .453;

Ineligible $=.107 ; \mathrm{N}=2077$.

T-ratios in parentheses below coefficients. 
Table 7

Impact of Eliminating Ineligibility

on Means of Quality Indicators

\begin{tabular}{|c|c|c|c|}
\hline \multirow{2}{*}{$\begin{array}{c}\text { Career } \\
\text { Management } \\
\text { Field } \\
\end{array}$} & \multirow{2}{*}{ Variable } & \multicolumn{2}{|c|}{ Mean } \\
\hline & & Actua 1 & No Eligibility \\
\hline \multirow[t]{5}{*}{ Infantry } & HS Grad & 0.907 & 0.889 \\
\hline & GED & 0.020 & 0.026 \\
\hline & AFQT & 0.475 & 0.473 \\
\hline & SQT & 0.113 & 0.003 \\
\hline & SQT Level & 0.152 & 0.112 \\
\hline Mechanical & HS Grad & 0.870 & 0.848 \\
\hline \multirow[t]{4}{*}{ Maintenance } & GED & 0.034 & 0.035 \\
\hline & AFQT & 0.407 & 0.405 \\
\hline & SQT & 0.156 & 0.076 \\
\hline & SQT Leve 1 & 0.084 & 0.068 \\
\hline \multirow[t]{5}{*}{ Administration } & HS Grad & 0.910 & 0.904 \\
\hline & GED & 0.019 & 0.019 \\
\hline & AFQT & 0.473 & 0.471 \\
\hline & SQT & 0.013 & -0.053 \\
\hline & SQT Level & 0.120 & 0.101 \\
\hline
\end{tabular}

A11 "No ineligibility" simulations based on $\theta=-1, p=-.5$, which fit the data slightly better than other values. 
This expectation is confirmed in Table 7, where mean values of the quality indicators for those who re-enlist are compared to means simulated on the assumption that all those who want to re-enlist $(R>0)$ are allowed to do so. While the difference in SQT level for infantry is of perhaps moderately important magnitude, the remaining differences are smal1. (The large proportionate change in SQT is misleading: because our SQT variable is normed to have mean zero and standard deviation of one, the SQT changes are only a tenth of a standard deviation for infantry and smaller for the two other occupation groups.)

\section{CONCLUSIONS}

Organizations like the Army with relatively "egalitarian" pay structures offer lower relative pay to those with the best earnings alternatives and higher relative pay to those with weaker options. Assuming some commonality in the attributes which are valued by civilian employers and by the military, this suggests the possibility of difficulty in retaining those the Army would most wish to keep. If relative pay considerations make the Army less attractive for its best enlistees, there are two ways to avoid losing them. First, nonpecuniary factors might make reenlisting particularly attractive for high-quality enlistees--because success in the Army makes staying more rewarding (apart from dollar rewards), or because those who find the Army most attractive end up doing the best job, or because superior enlistees' commanding officers find ways to make the option of re-enlisting attractive. Second, the Army may have more individuals willing to re-enlist than it needs and be able to select the best from among those who would like to re-enlist.

The evidence presented in this paper suggests that there is a significant tendency for those with high AFQT scores not to re-enlist. Reenlistment patterns of high school graduates and nongraduates are less clear-cut: graduates are more likely to be eligible to re-enlist, but they were generally (i.e., in infantry and administration but not mechanical maintenance) less like to do so.

If one judges "quality" by SQT scores, or the level of the SQT taken (which depends on grade level and hence prior promotions), the quality of those who re-enlist looks a good deal better. Those with higher SQT scores are consistently more likely to be eligible to re-enlist (which is hardly surprising) but also generally more likely to want to do so. The same 
holds for SQT level.

A plausible conjecture is that the pecuniary and nonpecuniary rewards of a job well done are more likely to trigger re-enlistment if "the job" cannot be performed in the civilian sector. If one enjoys doing administrative work because one does it well, one can do this in either the military or the civilian market, and so the nonpecuniary factors would contribute little to retention. If one derives satisfaction from superior performance in infantry occupations, however, there may be few civilian opportunities to use these skills. ${ }^{7}$ However, in fact there was little evidence that successful performance encouraged re-enlistment in infantry more than it did in mechanical maintenance and administration. The positive relationship between SQT performance and re-enlistment is probably therefore due to those who perform better either receiving better nonpecuniary compensation or having a stronger preference for "military life" (which is common across occupations). Because the former but not the latter would plausibly occur in civilian firms as we11, understanding the positive SQT-retention relationship deserves further study.

Finally, using a relatively broad measure of ineligibility, only 11 to 14 percent of those completing their first term of service are ineligible to re-enlist. While those excluded are less likely to be high school graduates or have a high SQT Score or level, their exclusion raises the average quality indicators of those re-enlisting by quite small amounts. This result should not be taken to mean that restricting eligibility is unimportant. It may (and probably does) have a more significant impact on some important dimensions of performance which I cannot measure (e.g., excluding those with bad attitude). Moreover, in assessing the impact of eligibility bars, I implicitly took performance as given, so that the effect of eligibility standards on incentives to improve performance were necessarily ignored. Indeed, it may well be that the link between retention and good SQT scores is easier to understand if one stresses "effort" rather than "ability" to start with.

The similarity of the effects of SQT scores on retention across occupation groups, noted above, is only an example of a more general robustness

\footnotetext{
${ }^{7}$ Quester et al. (1985, vol. I, pp. 87-88) calculated the ratio of civilian jobs with relevant skilis to number currently enlisted for various military occupations. They found no civilian counterpart for the jobs of 99 percent of those in our infantry sample, for 8 percent in mechanical maintenance, and for 18 percent in administration.
} 
of the findings across fields. The main findings were also fairly insensitive to variations in the values assumed for hard-to-identify parameters of the formal model. The simple tabular results showed similar patterns for both 1982-84 and 1985-87 decisions, despite the lower scores on traditional quality indicators for the former group. Overal1, one does see the robustness one hopes to see at the end of an empirical undertaking of this sort. 


\section{Table A1}

Outcomes by Enlistee Characteristics

Inf antry, 1982-84

\begin{tabular}{|c|c|c|c|c|}
\hline \multirow{3}{*}{ Characteristic } & \multicolumn{3}{|c|}{ Percent Probability of } & \multirow{3}{*}{$\begin{array}{l}\text { Number } \\
\text { of Case }\end{array}$} \\
\hline & \multicolumn{3}{|c|}{ Norma 1} & \\
\hline & Re-enlistment & Separation & Ineligibility & \\
\hline AFQT $1-30$ & 32 & 40 & 28 & 3861 \\
\hline AFQT $31-49$ & 31 & 40 & 29 & 1746 \\
\hline AFQT $50-64$ & 29 & 47 & 24 & 770 \\
\hline AFQT $65+$ & 28 & 56 & 17 & 1207 \\
\hline Education < HS Grad & 27 & 37 & 36 & 2834 \\
\hline Education = GED & 31 & 42 & 27 & 248 \\
\hline Education = HS Grad & 33 & 47 & 20 & 4508 \\
\hline$S Q T<-.5$ & 29 & 40 & 31 & 1566 \\
\hline SQT -.5 to .5 & 33 & 41 & 26 & 2866 \\
\hline SQT $>.5$ & 35 & 44 & 21 & 2176 \\
\hline SQT Level = 1 & 27 & 44 & 29 & 5823 \\
\hline SQT Level > 1 & 66 & 30 & 4 & 879 \\
\hline SQI Level Missing & 18 & 51 & 30 & 888 \\
\hline
\end{tabular}


Table A2

Outcomes by Enlistee Characteristics

Mechanical Maintenance, 1982-84

\begin{tabular}{|c|c|c|c|c|}
\hline \multirow{3}{*}{ Characteristic } & \multicolumn{3}{|c|}{ Percent Probability of } & \multirow{3}{*}{$\begin{array}{l}\text { Number } \\
\text { of Cases }\end{array}$} \\
\hline & \multicolumn{3}{|c|}{ Norma 1} & \\
\hline & Re-enlistment & Separation & Ineligibility & \\
\hline AFQT $1-30$ & 34 & 43 & 23 & 3092 \\
\hline AFQT $31-49$ & 28 & 47 & 25 & 1387 \\
\hline AFQT $50-64$ & 27 & 52 & 20 & 600 \\
\hline AFQT $65+$ & 28 & 51 & 20 & 635 \\
\hline Education < HS Grad & 27 & 42 & 31 & 1794 \\
\hline Education $=$ GED & 28 & 40 & 32 & 202 \\
\hline Education = HS Grad & 33 & 48 & 19 & 3727 \\
\hline$S Q T<-.5$ & 32 & 43 & 25 & 635 \\
\hline SQT -.5 to .5 & 36 & 42 & 27 & 874 \\
\hline SQT $>.5$ & 39 & 45 & 16 & 647 \\
\hline SQT Level $=1$ & 29 & 46 & 25 & 1853 \\
\hline SQT Level > 1 & 71 & 26 & 2 & 353 \\
\hline SQT Leve 1 Missing & 28 & 48 & 24 & 3519 \\
\hline
\end{tabular}


Outcomes by Enlistee Characteristics

Administration, 1982-84

\begin{tabular}{|c|c|c|c|c|}
\hline \multirow{3}{*}{ Characteristic } & \multicolumn{3}{|c|}{ Percent Probability of } & \multirow{3}{*}{$\begin{array}{l}\text { Number } \\
\text { of Cases }\end{array}$} \\
\hline & \multicolumn{3}{|c|}{ Norma 1} & \\
\hline & Re-enlistment & Separation & Ineligibility & \\
\hline AFQT $1-30$ & 52 & 31 & 18 & 621 \\
\hline AFQT $31-49$ & 47 & 35 & 18 & 515 \\
\hline AFQT $50-64$ & 43 & 38 & 19 & 284 \\
\hline AFQT $65+$ & 31 & 58 & 11 & 529 \\
\hline Education < HS Grad & 42 & 28 & 30 & 306 \\
\hline Education = GED & 54 & 19 & 26 & 68 \\
\hline Education $=$ HS Grad & 44 & 43 & 13 & 1579 \\
\hline$S Q T<-.5$ & 37 & 45 & 17 & 398 \\
\hline SQT -.5 to .5 & 49 & 36 & 15 & 637 \\
\hline SQT $>.5$ & 49 & 41 & 11 & 557 \\
\hline SQT Leve $1=1$ & 42 & 42 & 16 & 1357 \\
\hline SQT Level > 1 & 66 & 28 & 6 & 264 \\
\hline SQT Level Missing & 31 & 43 & 26 & 332 \\
\hline
\end{tabular}


Table A4

Re-enlistment Mode1 for Infantry

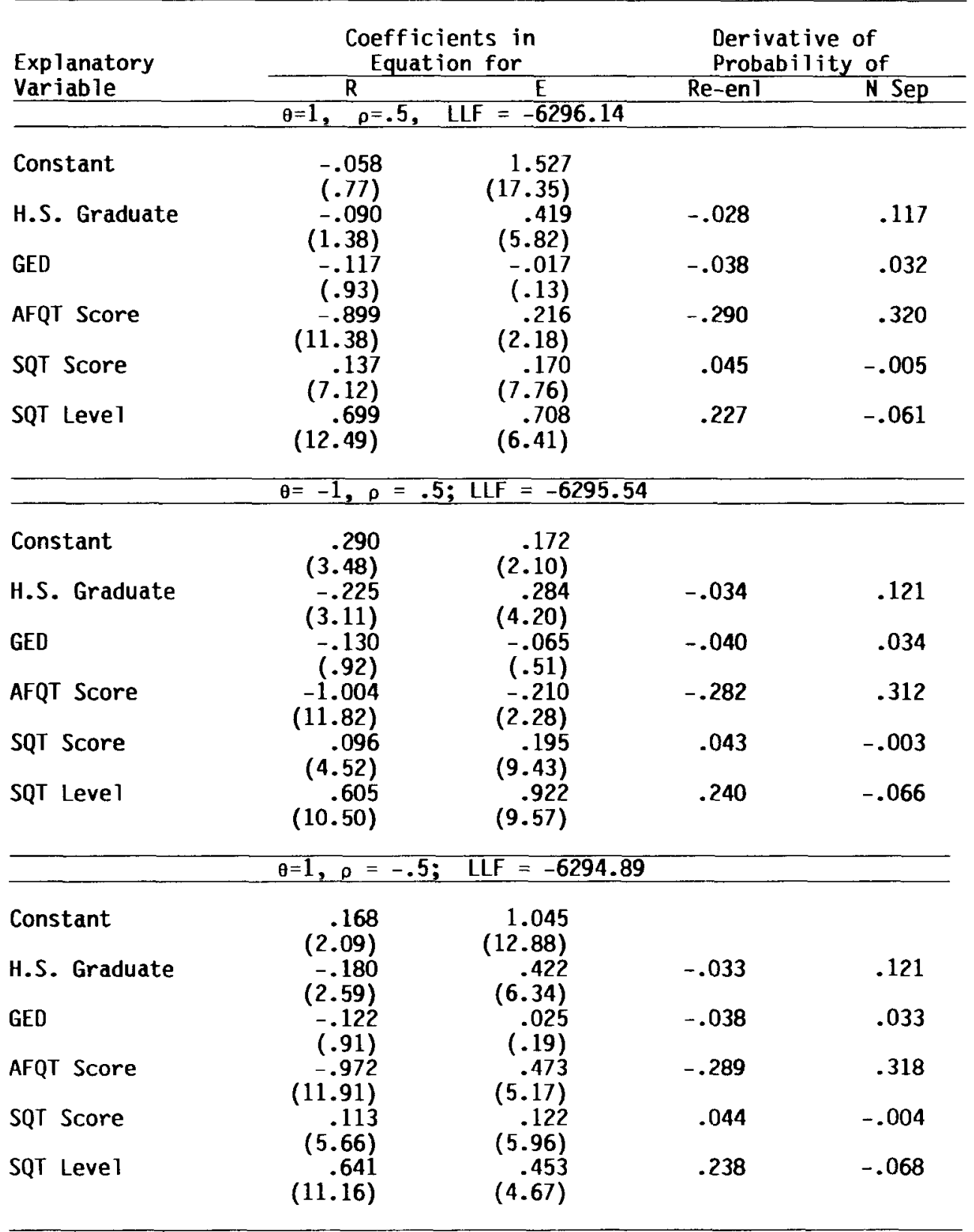


Table A5

Re-enlistment Model for Mechanical Maintenance

\begin{tabular}{|c|c|c|c|c|}
\hline \multirow{2}{*}{$\begin{array}{l}\text { Explanatory } \\
\text { Variable }\end{array}$} & \multicolumn{2}{|c|}{$\begin{array}{c}\text { Coefficients in } \\
\text { Equation for }\end{array}$} & \multicolumn{2}{|c|}{$\begin{array}{l}\text { Derivative of } \\
\text { Probability of }\end{array}$} \\
\hline & $\mathrm{R}$ & $E$ & Re-en 1 & N Sep \\
\hline & \multicolumn{4}{|c|}{$\theta=1, \quad \rho=.5, \quad$ LLF $=-4831.84$} \\
\hline Constant & \multirow{6}{*}{$\begin{array}{r}-.240 \\
(3.18) \\
.063 \\
(1.02) \\
. .205 \\
(1.72) \\
-.586 \\
(5.88) \\
.122 \\
(5.81) \\
.643 \\
(7.85)\end{array}$} & $\begin{array}{r}1.420 \\
(15.80)\end{array}$ & \multirow[b]{2}{*}{.024} & \multirow[b]{2}{*}{.072} \\
\hline H.S. Graduate & & $\begin{array}{r}.504 \\
(7.06)\end{array}$ & & \\
\hline GED & & $\begin{array}{r}.140 \\
(.97)\end{array}$ & .076 & -.045 \\
\hline AFQT Score & & $\begin{array}{r}.401 \\
(3.08)\end{array}$ & -.216 & .278 \\
\hline SQT Score & & $\begin{array}{r}.126 \\
(5.17)\end{array}$ & .045 & -.019 \\
\hline SQT Level & & $\begin{array}{r}.371 \\
(2.66)\end{array}$ & .239 & -.154 \\
\hline \multicolumn{5}{|c|}{$\theta=-1, \quad \rho=.5 ; \mathrm{LLF}=-4831.05$} \\
\hline Constant & \multirow{6}{*}{$\begin{array}{r}.140 \\
(1.69) \\
-.097 \\
(1.42) \\
.149 \\
(1.14) \\
-.724 \\
(6.78) \\
.092 \\
(4.06) \\
. .585 \\
(6.83)\end{array}$} & $\begin{array}{l}.041 \\
(.49)\end{array}$ & \multirow[b]{2}{*}{.015} & \multirow[b]{2}{*}{.083} \\
\hline H.S. Graduate & & $\begin{array}{r}.411 \\
(6.20)\end{array}$ & & \\
\hline GED & & $\begin{array}{r}.220 \\
(1.68)\end{array}$ & .067 & -.031 \\
\hline AFQT Score & & $\begin{array}{l}.018 \\
(.15)\end{array}$ & -.211 & .275 \\
\hline SQT Score & & $\begin{array}{r}. .160 \\
(6.96)\end{array}$ & & -.016 \\
\hline SQT Leve1 & & $\begin{array}{r}.648 \\
(5.52)\end{array}$ & .241 & -.147 \\
\hline \multicolumn{5}{|c|}{$\theta=1, \quad \rho=-.5 ; \quad$ LLF $=-4830.82$} \\
\hline Constant & \multirow{6}{*}{$\begin{array}{c}.013 \\
(.16) \\
-.046 \\
(.69) \\
.168 \\
(1.31) \\
-.690 \\
(6.64) \\
.107 \\
(4.89) \\
.623 \\
(7.17)\end{array}$} & $\begin{array}{r}.996 \\
(12.15)\end{array}$ & \multirow[b]{2}{*}{.016} & \multirow[b]{2}{*}{.081} \\
\hline H.S. Graduate & & $\begin{array}{r}.461 \\
(7.05)\end{array}$ & & \\
\hline GED & & $\begin{array}{l}.094 \\
(.72)\end{array}$ & .069 & -.033 \\
\hline AFQT Score & & $\begin{array}{r}.548 \\
(4.60)\end{array}$ & -.216 & .276 \\
\hline SQT Score & & $\begin{array}{r}.084 \\
(3.75)\end{array}$ & .046 & -.018 \\
\hline SQT Level & & $\begin{array}{r}.179 \\
(1.51)\end{array}$ & .243 & -.149 \\
\hline
\end{tabular}


Table A6

Re-enlistment Model for Administration

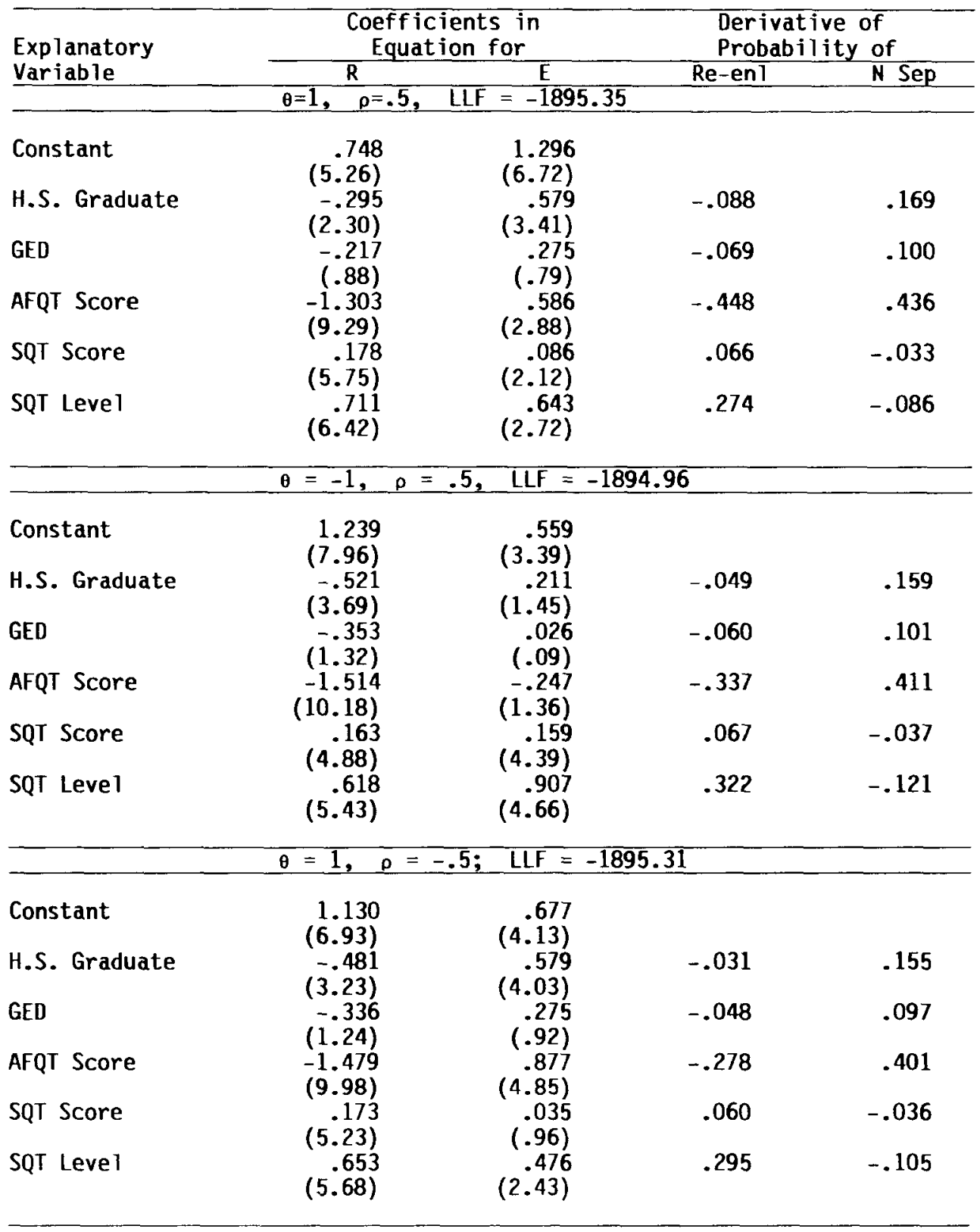




\section{REFERENCES}

Baldwin, R. and Daula, T.

(1985) Modeling the Retention Behavior of First-Term Military Personne 1. Research in Labor Economics, 7: (ed.) R. Ehrenberg. Greenwich CT: JAI Press.

Berndt, E., Ha11, B., Ha11, R., and Hausman, J.

(1974) Estimation and Inference in Nonlinear Structural Models. Annals of Economic and Social Measurement, 3: 653-665.

Borjas, G.

(1987) Self-Selection and the Earnings of Immigrants. American Economic Review, 77: 531-553.

Brown, C. and Medoff, J.

(1989) The Employer Size-Wage Effect. Journal of Political Economy, 97: $1027-1059$.

Daula, T. and Smith, D.A.

(1986) Recruiting Goals, Enlistment Supply, and Enlistments in the U.S. Army. Army Manpower Economics, (ed.) C. Gilroy. Boulder Co: Westriew Press.

DeVany, A. and Saving, T.

(1982) Life Cycle Job Choice and the Demand and Supply of Entry Level Jobs - Some Evidence from the Air Force. Review of Economics and Statistics, 64: 457-465.

The Economist.

(1989) Oxford's Fading Charms. July 8.

Ellwood, D. and Wise, D.

(1987) Uncle Sam Wants You - Sometimes: Military Enlistments and the Youth Labor Market. Public Sector Payrolls, (ed.) D. Wise. Chicago: University of Chicago Press. 
Fisher, A.

(1969) The Cost of the Draft and the Cost of Ending the Draft. American Economic Review, 59: 239-254.

Foulkes, F.

(1980) Personnel Policies in Large Nonunion Companies. Englewood Cliffs, N.J.: Prentice-Hall.

Grafton, F. and Horne, D.

(1985) An Investigation of Alternatives for Setting Second-to-Third Tour Reenlistment Standards. Technical Report 690, U.S. Army Research Institute.

Heckman, J. and Sedlacek, G.

(1986) Heterogeneity, Aggregation, and Market Wage Functions: An Empirical Model of Self-Selection in the Labor Market. Journal of Political Economy, 93: 1077-1125.

Hogan, P. and Smith, D.A.

(1988) The Army College Fund: Effects on Attrition, Re-enlistment, and Cost. U.S. Army Research Institute, Unpublished Paper.

Muse11, R.M.

(1986) Employee Turnover in the Federal Government. Congressional Budget office Special Study.

$0 i, W$.

(1967) The Economic Costs of the Draft. American Economic Review, 57: 39-62.

(1983a) Fixed Employment Costs of Specialized Labor. The Measurement of Labor Cost, (ed.) J. Tripplett. Chicago: University of Chicago Press.

(1983b) Heterogeneous Firms and the Organization of Production. Economic Inquiry, 21: 147-171. 
Quandt, R. and Goldfeld, S.

(1984) - GQOPT3/1. Princeton University.

Quester, A. et al.

(1985) National Manpower Inventory Final Report. Alexandria VA: Center for Naval Analyses, three volumes.

Rosen, S.

(1982) Output, Income, and Rank in Hierarchical Firms. Bell Journal of Economics, 13: 311-323.

Roy, A.D.

(1951) Some Thoughts on the Distribution of Earnings. Oxford Economic Papers, 3: 135-146.

Slackman, J.

(1986) Quality Soldiers: Costs of Manning the Active Army. Congressional Budget office Study.

Smith, D.A., Sylwester, S., and Villa, C.

(1989) Army Re-enlistment Models. Paper presented at U.S. Army Research Institute Conference.

Ward, M. and Tan, H.

(1985) The Retention of High-Quality Personnel in the U.S. Armed Forces, Rand Report R-3117-MIL.

Warner, J. and Solon, G.

(1989) Models of First-Term Attrition and Re-enlistment in the U.S. Army. Paper presented at U.S. Army Research Institute Conference. 